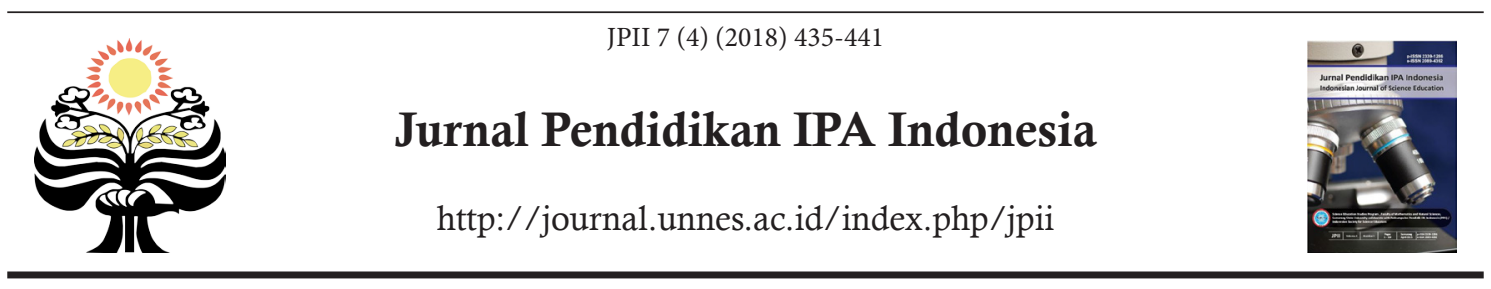

\title{
ENHANCING MASTERY OF EARTH SCIENCE CONCEPT OF PROSPECTIVE PHYSICS TEACHERS THROUGH INTERACTIVE CONCEPTUAL INSTRUCTION SUPPORTED BY VISUALIZATION AND GRADS
}

\author{
H. Johan*1, A. Suhandi ${ }^{2}$, A. R. Wulan ${ }^{3}$, Sipriyadi $^{4}$, A. Herawati ${ }^{5}$ \\ ${ }^{1}$ Physics Education Program, Mathematics and Natural Sciences Education Department, \\ Universitas Bengkulu, Indonesia \\ ${ }^{2}$ Physics Education Program, Universitas Pendidikan Indonesia, Bandung, Indonesia \\ ${ }^{3}$ Biology Education, Universitas Pendidikan Indonesia, Bandung, Indonesia \\ ${ }^{4}$ Biology Department, Universitas Bengkulu, Indonesia \\ ${ }^{5}$ Tunghai University, Taiwan, Province of China
}

DOI: $10.15294 /$ jpii.v7i4.9799

Accepted: July 28 $8^{\text {th }}, 2018$. Approved: December 10 $0^{\text {th }}, 2018$. Published: December $29^{\text {th }}, 2018$

\begin{abstract}
Most all of earth and space science concepts are unobservable and require reasoning. Unobservable concepts have made prospective physics teachers found it hard to understand the concepts correctly. It needs visualization to help understand the concepts easily. The aim of this study was to enhance the mastery concept of earth science topic especially the earth atmosphere using interactive conceptual with visualizations and authentic data analysis with GrADS (Grid Analysis Display System). There were 23 prospective physics teachers in Bengkulu, Indonesia participated in this study. A convenience sampling technique was employed in this study. This study used pre-experimental, one group pretest-posttest design. The data were collected using pretest and posttest, questionnaires, and observation sheets. The pretest and posttest were analyzed quantitatively, while the questionnaires were analyzed qualitatively. The results showed that the prospective physics teachers' concept mastery improved from no mastery to compete with the average normalized gain of 0.64 (medium category). $30.44 \%$ of the prospective physics teachers obtained the $\mathrm{N}$-gain score in the high category and $69.56 \%$ obtained the $\mathrm{N}$-gain score in the moderate category. This compilation gave them experience about the real condition of solar radiation in Indonesian atmosphere during their learning activity. It concluded that the earth science learning using interactive conceptual instruction supported by visualization and GrADS could enhance the students' concept mastery.
\end{abstract}

(C) 2018 Science Education Study Program FMIPA UNNES Semarang

Keywords: earth science, mastery concept, visualization

\section{INTRODUCTION}

Utmost of earth atmosphere phenomena are indirectly observable which require favorable reasoning to understand. Therefore, media assistance are needed to explain the earth atmosphere concepts due to visualize the imaginary, abstract

*Correspondence Address

E-mail: hennyjohan88@gmail.com concepts (Bilici et al., 2011; Park, 2013; Sunderlin, 2009). It was also reinforced by the previous investigation that about $78 \%$ of the future science teachers considered that geoscience materials were fairly convoluted and abstract which therefore made them difficult to understand (Rosnita, 2016; Miller \& Brewer, 2010). Hence, a neatlyconstructed learning on earth atmosphere should be designed in order to assist future science teach- 
ers to improve their concept mastery (Jolley et al., 2012). A research carried out in Bengkulu using the Search, Solve, Create, and Share (SSCS) learning model indicated a slight enhancement of mastery concept having the N-Gain score of 0.49 and belonged to the 'moderate' category (Johan et al., 2018a). The Interactive Conceptual Interaction (ICI) applied in this research focused on evocative learning aiming at improving the future science teachers' mastery of earth and space concepts. Moreover, this study provided the established ICI model supported by authentic data of atmospheric phenomena as the main materials.

One of the ways to advance the concept mastery is by using a scientific model to aid learners in comprehending the concepts (King, 2010; Park, 2013; Sibley, 2009; Saribas et al., 2016). According to Bloom, notion mastery is the capability to comprehend the substance of learning expansively, and be able to offer clarification, as well as apply it (Anderson, 2010). Mastery concept is the fundamental aspect of learning, and the use of technology has proven to overcome the obstacles as the harnessing of science has become an educational research trend. Smith \& Bermea (2012) applied the sketching technique as the alternative conception of the plate tectonics. However, media visualization has not been commonly used in Bengkulu particularly on the earth and space topic. Furthermore, previous studies have shown the improvement of earth and science concepts through the use of sketching, visualization, and animation techniques (Prain et al., 2009; Smith \& Bermea, 2012; Samsudin et al., 2016; Kali \& Linn, 2008). Other than that, analogies, real replicas or diagram were also utilized in some research to advance future science teachers' concept mastery (Jee et al., 2010; Sibley, 2009; Passmore et al., 2014). In other words, technology has facilitated the interpretation of abstract, unobservable concepts such as earth and space. In this case, the animation is most- adapted technology to help students catch a proper understanding of such concepts. Profound comprehension of the connection between scientific independence, technology, and pro-environmental behaviors are necessary for students to support them in various courses (Bezen et al., 2016; Santos \& Arroio, 2016; Kastens, 2010).

Geoscience visual representation could aid students for the betterment of their understanding. This research presented multi modus visualization such as animation, graphs, and figures which configured each other to ease the students in comprehending the concepts. The visualization of this research emerged as the results of authen- tic data analysis with GrADS, which has never been done before. In addition, the results of this research could be later used to support students' thinking process as well as give varying learning experience. The authentic data were computed using the Matrix Laboratory (MATLAB) to produce 3-Dimension visualization (Werts \& Hinnov, 2011; Ellwein et al., 2014) while the Indonesian atmospheric data were analyzed using the Grid Analysis Display System (GrADS). In addition, a module was developed referring to the authentic data.

Captivating students' attention to interpreting the GrADS data visualization would be a remarkable learning experience which was expected to result in the improvement of earth and space concept mastery. Making use of the GrADS system in a learning process particularly on the earth and science topic has not been published yet. The GrADS and MATLAB results were approximately indistinguishable yet the GrADS was fairer to be used than the MATLAB.

With this in mind, the researchers frankly said that this research intended to enhance the earth science concept mastery of the future physics teachers for the analysis level especially the earth atmosphere employing the interactive conceptual instruction with the aid of GrADS and visualization.

\section{METHODS}

Pre-experimental research was conducted with one group pretest-posttest research design. 23 prospective physics teachers were involved in this study. There were three stages of research including pre-implementation, implementation of one group pre-test post-test design, and postimplementation. In the pre-implementation, kinds of media for visualization to every concept were recognized qualitatively to advance prospective physics teachers' concept mastery.

The studied materials included the composition of air mass, atmospheric pressure, atmospheric temperature, the ozone layer, and incoming solar radiation. In this stage, the learning activities using the ICI model and data collection tools were created. There were four stages in the learning; the focus of concept, textbook usage, interactive classroom, research-based materials. The research-based materials were the results of the GrADS authentic data analysis which measured the net solar radiation in January-December 1990. The output of the GrADS was the display of Indonesian atmosphere actual condition. These visualizations intended to assist the fu- 
ture physics teachers to understand the concepts.

In the implementation step, the ICI was run to 23 future physics teachers in Bengkulu, Indonesia. The participant had never joined the Earth and Space course before. These participants were chosen by using the Convenience Sampling technique. The data of prospective physics teachers' mastery were obtained from the pretest and posttest. The mastery differences found in the pretest and posttest score were then computed as the N-Gain <g> (Hake in Jackson et al., 2008).

Description:

$$
<g>=\frac{S_{\text {post }}-S_{\text {pre }}}{S_{\max }-S_{\text {pre }}}
$$

$\mathrm{S}_{\text {pre }}=$ pretest score $; \mathrm{S}_{\text {post }}=$ posttest score $; \mathrm{S}_{\max }=$ maximum score

Some instruments were needed in this research to collect the data. The quantitative data of concept mastery were collected through multiple choice questions while the qualitative data of prospective physics teachers' responses were collected through open-ended questions. The instruments employed were authenticated by a proficient team. There were four professionals partook in authenticating the instruments. The instruments used in this research were verified by 34 prospective physics teachers. Based on the experts and instrument implementation, it concluded that the research' instruments were valid and reliable. The sample of question is as follows: "Based on the graph of annual solar movement, the incoming solar radiation on $23,5^{\circ}$ of the northern hemisphere at summer solstice is...." (Note: BBS is southern hemisphere; BBU is northern hemisphere; $0^{\circ}$ is equator).

The classroom activities carried out in this lesson are presented in Table 1

\section{Table 1. The Classroom Activities}

The focus of concept:

Picturizations as to help comprehend the concept

\begin{tabular}{l} 
Textbook usage: \\
Library research to keep \\
up with the latest terms, or \\
keywords of the visualized \\
concepts \\
\hline Research-based materials: \\
The output of the GrADS \\
program which displays the \\
actual Indonesian atmosphere \\
used to support the students to \\
comprehend the notion
\end{tabular}

Interaction: Interactive discussions among students during learning process

The output of the GrADS actual Indonesian atmosphere comprehend the notion

In the pre-implementation stage, the type visualization was qualitatively examined for each concept. The visualizations were in the form of animations, figure, graphs, and GrADS picturization. The examination of visualization type was to ensure that the students have had an appropriate understanding to avoid misunderstanding, also, advance their thinking skills. These kinds of visualization were then adopted to the developed learning program.

\section{RESULTS AND DISCUSSION}

This research aimed to describe the enhancement of prospective physics teachers' concept mastery known from the differences between the post-test and pre-test results. The students' early knowledge was known through the pre-test and the increase was examined through the post-test. The below Table informs the pre- and post-test of the students.

Table 2. The Data of Correct Answer at Pre-Test and Post-Test

\begin{tabular}{lcccccc}
\hline $\begin{array}{c}\text { Understand- } \\
\text { ings }\end{array}$ & $\begin{array}{c}\text { Compositions } \\
\text { of air mass }\end{array}$ & $\begin{array}{c}\text { Atmospheric } \\
\text { pressure }\end{array}$ & $\begin{array}{c}\text { Atmospheric } \\
\text { temperature }\end{array}$ & $\begin{array}{c}\text { Atmospheric } \\
\text { temperature }\end{array}$ & $\begin{array}{c}\text { Ozone } \\
\text { layer }\end{array}$ & $\begin{array}{c}\text { Incoming } \\
\text { solar } \\
\text { radiation }\end{array}$ \\
$\begin{array}{l}\text { Taxonomy } \\
\text { level }\end{array}$ & $\begin{array}{c}\text { C2 } \\
\text { understanding }\end{array}$ & $\begin{array}{c}\text { C3 } \\
\text { applying }\end{array}$ & $\begin{array}{c}\text { C2 } \\
\text { understanding }\end{array}$ & $\begin{array}{c}\text { C3 } \\
\text { applying }\end{array}$ & $\begin{array}{c}\text { C4 } \\
\text { analysis }\end{array}$ & $\begin{array}{c}\text { C4 } \\
\text { analysis }\end{array}$ \\
\hline $\begin{array}{l}\text { Correct answers } \\
\text { in Pre test }\end{array}$ & $13 \%$ & $30.5 \%$ & $52.1 \%$ & $39.1 \%$ & $30.5 \%$ & $47.8 \%$ \\
$\begin{array}{l}\text { Correct answers } \\
\text { in Post test }\end{array}$ & $30.5 \%$ & $95.7 \%$ & $100 \%$ & $91.3 \%$ & $47.8 \%$ & $95.7 \%$ \\
$\begin{array}{l}\text { Difference } \\
\text { between pre } \\
\text { and post }\end{array}$ & $17.5 \%$ & $65.2 \%$ & $47.9 \%$ & $55.2 \%$ & $17.3 \%$ & $47.9 \%$ \\
$\begin{array}{l}\text { N-Gain (Im- } \\
\text { provement) }\end{array}$ & 0.2 & 0.93 & 1 & & & \\
Category & low & high & high & high & low & high \\
\hline
\end{tabular}


Table 2 provides the dissimilar between the correct answers at pre-test and post-test for each concept; also, the improvement of pre-service physics teachers' mastery. The Bloom's revised taxonomy stages were adopted. The influence of the learning process was specified on the enhancement of mastery aspects (C2). Based on data displayed in Table 2, there was a shift in the students' mastery concept seen from the high increase of atmospheric pressure, atmospheric temperature, and incoming solar radiation mastery. Furthermore, there was $52.1 \%$ of correct answers on the pre-test for atmospheric temperature materials and $100 \%$ of correct answers on the post-test. This made it the highest improvement among others. On the other hand, there was only $13 \%$ of correct answers on the pre-test for air mass composition and was increased by $17.5 \%$ to become $30.5 \%$ on the post-test. However, the lowest increased was on the analysis (C4) of the ozone layer which scored an improvement of $17.3 \%$ although the other $\mathrm{C} 4$ of incoming solar radiation scored high (47.9\%).

Table 3. The Distribution of N-gain

\begin{tabular}{lcc}
\hline \multicolumn{1}{c}{ N-Gain } & Criteria & $\begin{array}{c}\text { Prospective Physics } \\
\text { Teachers (\%) }\end{array}$ \\
\hline$g>0,7$ & High & $30.44 \%$ \\
$0,3 \leq g \leq 0,7$ & Medium & $69.56 \%$ \\
$g<0,3$ & Low & none \\
\hline
\end{tabular}

Table 3 informs the enhancement distribution of concept mastery on each N-Gain level. A student's concept mastery was calculated from each student's understanding of all concepts. The data of the students' increase in all concept mas- tery elucidated that no one had low concept mastery and all of them categorized as the medium as the N-Gain average score was 0.69. It appears in Table 3 that $30.44 \%$ of future physics teachers were in the high category and other $69.56 \%$ of them were in the medium category.

Those remarkable improvements emerged as a result of the use of various visualization types. It seems that different type of visualization has a different impact. The learning of air mass composition, which scored the least, used tables and graphs. A distinct difference between the two $\mathrm{C} 4$ aspects was quite interesting. The $\mathrm{C} 4$ of incoming solar radiation, which scored higher, utilized the combination of animation and GrADS visualization. Supposedly, this compilation influenced their concept mastery in analysis level as it helped the students to understand the concepts easily and clearly. Furthermore, Table 3 shows that most students are in the high and medium category based on the $\mathrm{N}$-gain for concept mastery. The use of visualization media was closely related these pleasant results since it enabled students to watch the unobservable phenomena of Earth and Space especially the atmospheric. This was supported by the results of the questionnaires which revealed that most students considered media visualization, especially animation, as the most helpful aid.

The display of the GrADS output by analyzing the authentic data has given an expressive effect for the research. The findings indicated that the learning processes supported by researchbased materials had the advantage of being able to describe the actual condition of nature. The display of the GrADS output by analyzing the authentic data of real solar radiation in 1990 is presented in Figure 1.

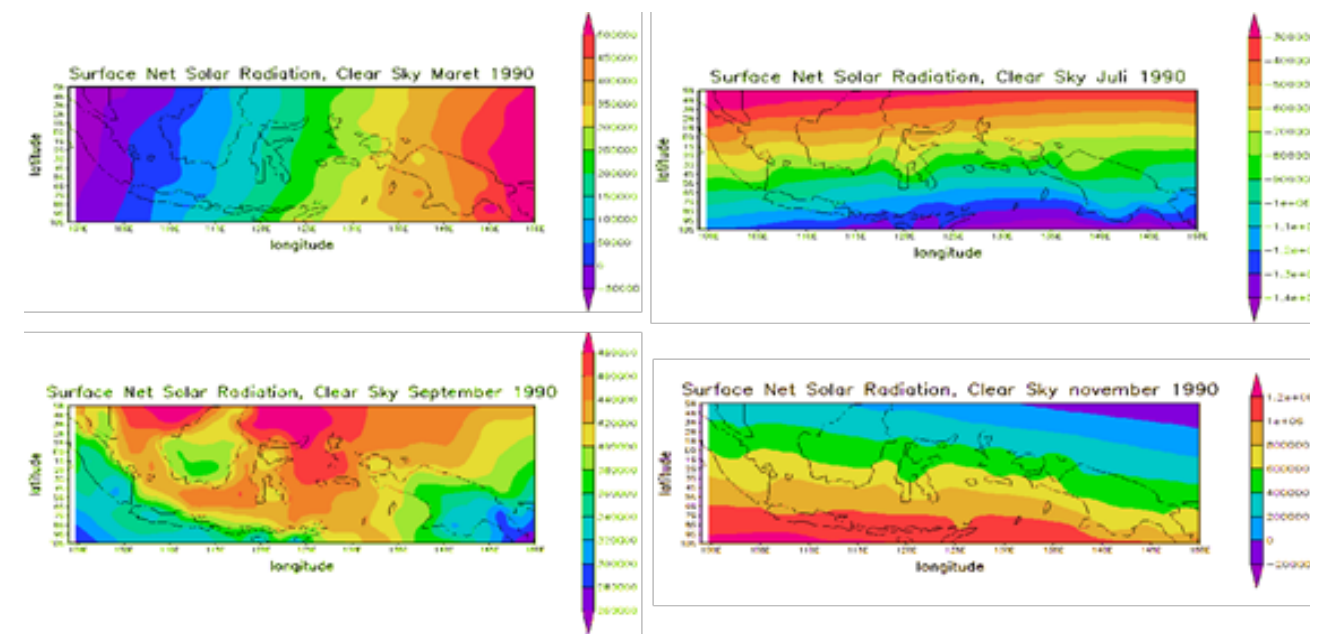

Figure 1. The GrADS Output Displaying Actual Condition of Indonesia Solar Radiation on the Atmosphere in March, July, September, and November 1990 
The above visualizations are the analysis results of surface net solar radiation from GrADS which is influenced by latitude and position during annual solar movement. The incoming solar radiation influences temperature and pressure in the atmosphere while the colors indicate the different amount of solar radiation. For instance, the northern hemisphere has surplus solar radiation on July and deficit of solar radiation in July 1990. Having such de- tails, this kind of visualization could support learning the atmospheric pressure, atmospheric temperature, and incoming solar radiation concepts and the correlation between each concept.

After being provided the actual condition of Indonesia Solar Radiation, the students were asked to relate the net solar radiation and the sun's motion during the year, which is seen in Figure 2.

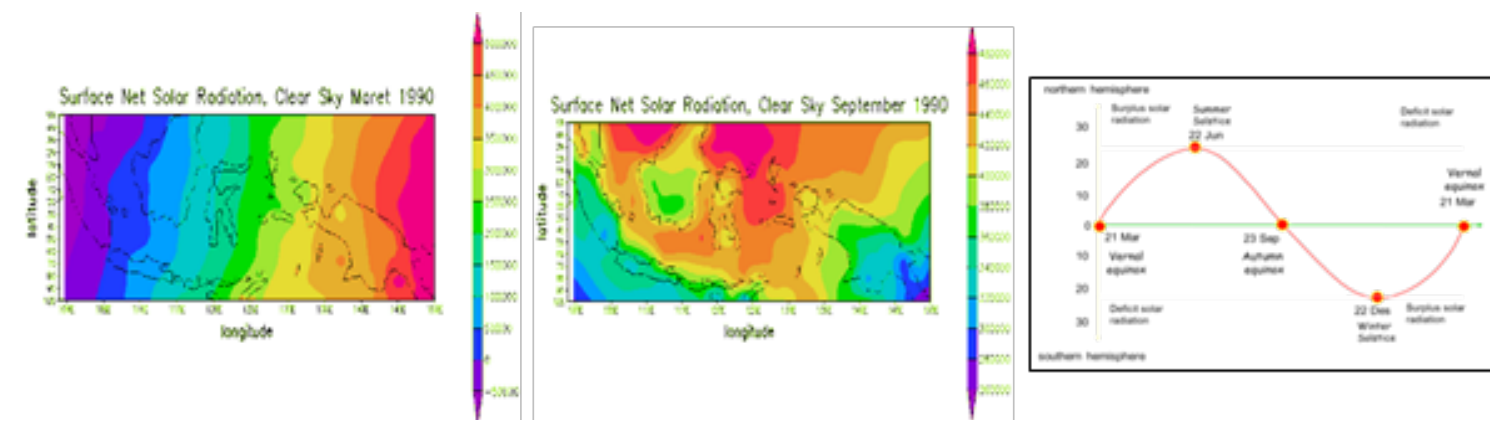

Figure 2. (a) and (b). The Surface Net Solar Radiation in Indonesia's Atmosphere on March and September 1990; (c). The Annual Solar Movement

The Figure $2 \mathrm{a}, 2 \mathrm{~b}$, and $2 \mathrm{c}$ are correlated with each other. Based on Figure $2 a$ and $2 b$, the students could obviously notice the distribution of solar radiation in Indonesia both on the northern and southern hemisphere while Figure 2c shows the annual solar movement. Therefore, the students could easily draw conclusion why the northern hemisphere of Indonesia has surplus solar Radiation in June 1990. This is parallel with Mountney (2009) who stated that animation that used in learning gives dynamic situational of an object and this is potential to explore logic thinking. Moreover, the concepts of incoming solar radiation and atmospheric temperature, as well as its correlation, could also be explained. This is similar with previous research elucidating that visualization could explain the correlation among various variables (Werts \& Hinnov, 2011). Therefore, it supports the opinion suggesting that the collaboration of visual media and authentic data in learning contributes to students' reasoning skills to reach the proper concept mastery (Johan et al., 2018a; Johan et al., 2018b). Improvement of mastery concept is also influenced by the learning process that stimulated student's curiosity and motivation. Similar research stated that virtual visualization as a game in learning activity could improve enthusiasm or interest in learning (Ismawati et al., 2014). Furthermore, this learning potentially enhances the spiritual aspect. It causes earth science learning helped by
GrADS could display the real condition of the earth atmosphere (Johan et al., 2018a; Johan et al., 2018b).

The use of visualization to ease the concept understanding was agreed upon by the students through the questionnaires. Based on the students' responses to the questionnaires, it summed up that: (1) The Earth and Space learning using visualizations was more interesting; (2) The use of visualization, especially animation, has helped them to comprehend the atmospheric concepts easier; (3) The animation was very clear and able to help to simplify the concepts; (4) Animations made the learnings became more enjoyable. Visualizations are also able to foster curiosity and motivation. These learning results were also supported by previous research that stated multimedia teaching materials including text, graphics, images, audio, video, and animation gave more significant effect on students' cognitive (Khoiriah et al., 2016). Other research reported that motivation was important factors for successful learning activities (McConnell \& Kraft, 2011; Lee \& Pang, 2013).

\section{CONCLUSION}

Based on the above results and discussion, it concluded that the earth atmosphere learning through conceptual interactive using visualizations was the potential to improve prospective 
physics teachers' concept mastery. The prospective physics teachers' concept mastery improved quite remarkably and categorized as medium based on the average N-Gain score of 0.64 . The visualization of solar radiation authentic data analyzed using the GrADS helped the students to understand the concept easier and gave them experience about the real Indonesia solar radiation. the improvement of prospective physics teachers' conceptual levels indicated that visualization made the learnings became more interesting and explored their thinking skills. Visualizations give the concept details plainly and showed the relationship of various variables or concepts in the earth atmospheric phenomena. It is expected for future research to exploit other phenomena to be displayed in classes for the betterment of preservice physics teachers' quality.

\section{REFERENCES}

Anderson, L. W., Krathwohl, D. R., Airasian, P. W. Cruikshank, K. A., Mayer, R. E., Pintrich, P. R., ... \& Wittrock, M. C. (2001). A Taxonomy for Learning, Teaching, and Assessing: A Revision of Bloom's Taxonomy of Educational Objectives, Abridged Edition. White Plains, NY: Longman.

Bezen, S., Aykutlu, I., \& Bayrak, C. (2016). Conceptual Comprehension of Pre-Service Physics Teachers Towards 1st Law of Thermodynamics. Journal of Turkish Science Education (TUSED), 13(1), 55-75.

Bilici, S. C., Armagan, F. O., Cakir, N. K., \& Yuruk, N. (2011). The development of an Astronomy Concept Inventory (ACI). Procedia-Social and Behavioral Sciences, 15(4), 2454-2458.

Colagrande, E. A., Martorano, S. A., \& Arroio, A. (2016). Assessment on How Pre-Service Science Teachers View the Nature Of Science. Journal of Turkish Science Education, 13(4), 173-184.

Carolan, J., Prain, V., \& Waldrip, B. (2008). Using Representations for Teaching and Learning in Science. Teaching Science: The Journal of the Australian Science Teachers Association, 54(1), 18-23.

Ellwein, A. L., Hartley, L. M., Donovan, S., \& Billick, I. (2014). Using Rich Context and Data Exploration to Improve Engagement with Climate Data and Data Literacy: Bringing a Field Station into the College Classroom. Journal of Geoscience Education, 62(4), 578-586.

Ismawati, F., Nugroho, S.E., \& Dwijananti, P. (2014). Penerapan Model Pembelajaran Conceptual Understanding Procedures untuk Meningkatkan Curiosty dan Pemahaman Konsep Siswa. Jurnal Pendidikan Fisika Indonesia. 10(1), 2227.
Jee, B. D., Uttal, D. H., Gentner, D., Manduca, C., Shipley, T. F., Tikoff, B., ... \& Sageman, B. (2010). Commentary: Analogical Thinking in Geoscience Education. Journal of Geoscience Education, 58(1), 2-13.

Johan, H., Suhandi, A., \& Wulan, A. R. (2018a). Grid Analysis Display System (GrADS) and Multi Modus Visualization in Earth Science Learning Mastery and Spiritual Aspect to Enhance Concept. Journal of Turkish Science Education (TUSED), 15(1), 109-127.

Johan, H., Suhandi, A., Wulan, A. R., \& Sipriyadi, S. (2018). Impact of Learning Earth Litosphere using Interactive Conceptual Instruction on Logic Thinking, Conceptual Understanding, and Spiritual Aspect Embedding. Jurnal Pendidikan Fisika Indonesia, 14(1), 7-17.

Jolley, A., Lane, E., Kennedy, B., \& Frappé-Sénéclauze, T. P. (2012). SPESS: A New Instrument for Measuring Student Perceptions in Earth and Ocean Science. Journal of Geoscience Education, 60(1), 83-91.

Kali, Y., \& Linn, M. C. (2008). Designing Effective Visualizations for Elementary School Science. The Elementary School Journal, 109(2), 181198.

Kastens, K. (2010). Commentary: Object and Spatial Visualization in Geosciences. Journal of Geoscience Education, 58(2), 52-57.

Khoiriah, K., Jalmo, T., \& Abdurrahman, A. (2016). The Effect of Multimedia-Based Teaching Materials in Science Toward Students' Cognitive Improvement. Jurnal Pendidikan IPA Indonesia, 5(1), 75-82.

King, C. J. H. (2010). An Analysis of Misconceptions in Science Textbooks: Earth Science in England and Wales. International Journal of Science Education, 32(5), 565-601.

Lee, P. L., \& Pang, V. (2013). Motivational Factors in Continuing Education an Academic Achievement of Adult Learners. Malaysian Journal of Learning and Instruction, 10, 57-77.

Mountney, N. P. (2009). Improving Student Understanding of Complex Spatial-Temporal Relationships in Earth Sciences Using Computer Animation and Visualization. Planet, 22(1), 72-77.

McConnell, D. A., \& van Der Hoeven Kraft, K. J. (2011). Affective Domain and Student Learning in the Geosciences. Journal of Geoscience Education, 59(3), 106-110.

Jackson, J., Dukerich, L., \& Hestenes, D. (2008). Modeling Instruction: An Effective Model for Science Education. Science Educator, 17(1), 10-17.

Miller, B. W., \& Brewer, W. F. (2010). Misconceptions of Astronomical Distances. International Journal of Science Education, 32(12), 1549-1560.

Park, S. K. (2013). The Relationship between Students' Perception of the Scientific Models and Their Alternative Conceptions of the Lunar 
Phases. Eurasia Journal of Mathematics, Science \& Technology Education, 9(3), 285-298.

Prain, V., Tytler, R., \& Peterson, S. (2009). Multiple Representation in Learning About Evaporation. International Journal of Science Education, 31(6), 787-808.

Rosnita, R. (2016). The Development of Laboratory-based Earth and Space Science Learning Model to Improve Science Generic Skills of Pre-service Teachers. Jurnal Pendidikan IPA Indonesia, 5(2), 171-176.

Samsudin, A., Suhandi, A., Rusdiana, D., Kaniawati, I., \& Coştu, B. (2016, June). Investigating the Effectiveness of an Active Learning Based-Interactive Conceptual Instruction (ALBICI) on Electric Field Concept. In Asia-Pacific Forum on Science Learning \& Teaching (Vol. 17, No. 1).

Santos, V. C., \& Arroio, A. (2016). The Representational Levels: Influences and Contributions to Research in Chemical Education. Journal of Turkish Science Education, 13(1), 3-18.

Saribaş, D., Doğança Küçük, Z., \& Ertepinar, H. (2016). Evaluating Effects of an Exhibition Visit on Pre-Service Elementary Teachers' Understandings of Climate Change. Journal of Turkish Science Education (TUSED), 13(1), 19-30.
Sibley, D. F. (2009). A Cognitive Framework for Reasoning with Scientific Models. Journal of Geoscience Education, 57(4), 255-263.

Smith, G. A., \& Bermea, S. B. (2012). Using Students' Sketches to Recognize Alternative Conceptions about Plate Tectonics Persisting from Prior Instruction. Journal of Geoscience Education, 60(4), 350-359.

Passmore, C., Gouvea, J. S., \& Giere, R. (2014). Models in Science and in Learning Science: Focusing Scientific Practice on Sense-Making. In International handbook of research in history, philosophy and science teaching (pp. 1171-1202). Springer, Dordrecht.

Sunderlin, D. (2009). Integrative Mapping of GlobalScale Processes and Patterns on "Imaginary Earth" Continental Geometries: A Teaching Tool in an Earth History Course. Journal of Geoscience Education, 57(1), 73-81.

Werts, S., \& Hinnov, L. (2011). A Simple Modeling Tool and Exercises for Incoming Solar Radiation Demonstrations. Journal of Geoscience Education, 59(4), 219-228. 